\title{
Bladder metastasis without hematuria, following radiation therapy for lung adenocarcinoma
}

\author{
Takahiro Kirisawa $^{1}\left[\right.$ (D) Manabu Okada ${ }^{1} \cdot$ Chisako Miura $^{2} \cdot$ Ichiro Miura $^{2}$
}

Received: 9 February 2021 / Accepted: 8 May 2021 / Published online: 27 May 2021

(c) The Author(s) 2021

\begin{abstract}
Bladder metastasis from lung adenocarcinoma is extremely rare. Unlike primary bladder urothelial tumors, the initial symptoms of this disease vary, and include pelvic pain, dysuria, and hematuria. There are few reports on cases without microscopic hematuria. An 86-year-old woman with a previous history of radiation therapy for lung adenocarcinoma complained of urinary frequency. A urinalysis was negative for hematuria and pyuria; thus, overactive bladder was suspected. However, the patient's symptom worsened considerably, and cystoscopy revealed bladder tumor. Transurethral resection of the bladder tumor was performed. Based on the histological, immunohistochemical examination and clinical history, the final pathological diagnosis was bladder metastasis from lung adenocarcinoma. The patient died 19 days after the operation due to severe disease progression. In this rare case, a patient with bladder metastasis from lung adenocarcinoma did not show microscopic hematuria. Cystoscopy and computed tomography helped to make a rapid and accurate diagnosis.
\end{abstract}

Keywords Bladder metastasis $\cdot$ Hematuria $\cdot$ Lung adenocarcinoma $\cdot$ Pollakiuria $\cdot$ Secondary tumor

\begin{tabular}{|c|c|}
\hline \multicolumn{2}{|c|}{ Abbreviations } \\
\hline $\mathrm{CT}$ & Computed tomography \\
\hline MRI & Magnetic resonance imaging \\
\hline OS & Overall survival \\
\hline $\mathrm{RP}$ & Retrograde pyelography \\
\hline TURBT & Transurethral resection of the bladder tumor \\
\hline
\end{tabular}

\section{Introduction}

Secondary cancers of the bladder are rare. The majority of cases occur due to direct spread from adjacent organs such as the prostate, lower gastrointestinal tract, and uterine cervical carcinomas. On the other hand, a smaller proportion of cancer metastasis occur due to lymphogenous or hematogenous pathways, as is sometimes observed in patients with skin, stomach, breast, or lung cancer. Secondary bladder

Takahiro Kirisawa

takahiro350301@gmail.com

1 Department of Urology, Hokkaido Social Work Association Obihiro Hospital, 2 Higashi 5-jo Minami 9-chome, Obihiro-shi, Hokkaido, Japan

2 Department of Pathology, Hokkaido Social Work Association Obihiro Hospital, 2 Higashi 5-jo Minami 9-chome, Obihiro-shi, Hokkaido, Japan neoplasms are reported to represent $2.3 \%$ of all malignant bladder tumors [1]. Cases of lung origin (squamous cell carcinoma, adenocarcinoma, small cell carcinoma) represent $2.8 \%$ of all secondary bladder neoplasms [1]. The most commonly reported symptom of bladder metastasis from lung cancer is gross or microscopic hematuria [2]. We herein report a case in which a patient was diagnosed with bladder metastasis from lung adenocarcinoma, without microscopic hematuria, in which the only symptom at presentation was pollakiuria.

\section{Case report}

An 86-year-old woman was diagnosed with left lung adenocarcinoma, stage T2aN0M0 in October 2018. One month after diagnosis, she received radiation therapy, without chemotherapy. In July 2020, she was referred to our department complaining of urinary frequency and urge incontinence, which had persisted for 1 week. A urinalysis was negative for hematuria and pyuria, therefore overactive bladder was suspected at first examination. Urine cytology was also negative. At return visit, investigations revealed normocytic anemia (hemoglobin $10.4 \mathrm{~g} / \mathrm{dl}$, mean cell volume $98.9 \mathrm{fl}$, white cell count $5.54 \times 10^{3} / \mu \mathrm{l}$, and platelet $203 \times 10^{3} /$ $\mu 1)$. Renal and liver function except for albumin were normal 
(creatinine $0.89 \mathrm{mg} / \mathrm{dl}$, blood urea nitrogen $17.0 \mathrm{mg} / \mathrm{dl}, \mathrm{C}$ reactive protein $0.39 \mathrm{mg} / \mathrm{dl}$, aspartate aminotransferase 22 IU/l, alanine aminotransferase 14 IU/l, alkaline phosphatase $170 \mathrm{IU} / \mathrm{l}$, and albumin $3.5 \mathrm{~g} / \mathrm{dl}$ ). Meanwhile, the value of lactate dehydrogenase was abnormal (251 IU/l). Frequency voiding chart revealed a total of 14 voiding episodes per day, with an average voided volume of $20 \mathrm{ml}$. Due to the severe and worsening symptoms, imaging studies were performed to detect organic disease. Cystoscopy showed a nodular tumor covered with calcification at the left top wall and mucosal folding change that involved the whole posterior wall. CT revealed a tumor $(9 \mathrm{~mm} \times 7 \mathrm{~mm})$ at the dome of bladder, thickening of the bladder wall (Fig. 1a), and right hydronephrosis. Tumor marker levels were within the normal range (carcinoembryonic antigen $3.1 \mathrm{ng} / \mathrm{ml}$, CA19-9 $3 \mathrm{U} / \mathrm{ml}$, CA125 13U/ml, SCC $1.5 \mathrm{ng} / \mathrm{ml}$, NSE $12.5 \mathrm{ng} / \mathrm{ml}$ ), which was the same as that at diagnosis of lung carcinoma. 10 days later the patient was debilitated by bilateral back pain, fatigue, and anorexia. CT revealed bilateral hydronephrosis (Fig. 1b). RP showed extensive bilateral strictures at the lower part of the ureters. MRI showed distinct boundary between bladder and uterus (Fig. 2a, b), and Papanicolaou stain of uterine cervix cytology was also negative, then presence of locally invasive cervical cancer was denied. CT and MRI revealed no space occupying lesion except for the bladder. Double-J stents were inserted bilaterally and TURBT was performed. The bladder wall was considerably solid and maximum bladder capacity was approximately $20 \mathrm{ml}$. HE staining showed a nodular and sheet-like growth pattern with massive necrosis in mainly lamina propria. Tumor cells were large round cells with pleomorphic enlarged nuclei and conspicuous mitosis (Fig. 2a, b). The tumor invaded the muscle layer of the bladder wall. The findings were consistent with poorly differentiated carcinoma. An immunohistochemical examination of formalin fixed paraffin embedded sections revealed that the tumor cells were positive for thyroid transcription factor (TTF-1), cytokeratin 7 (CK7), and GATA binding protein-3 (GATA3), and negative for cytokeratin 20 (CK20) (Fig. 3a-d), Napsin A, and Uroplakin III.
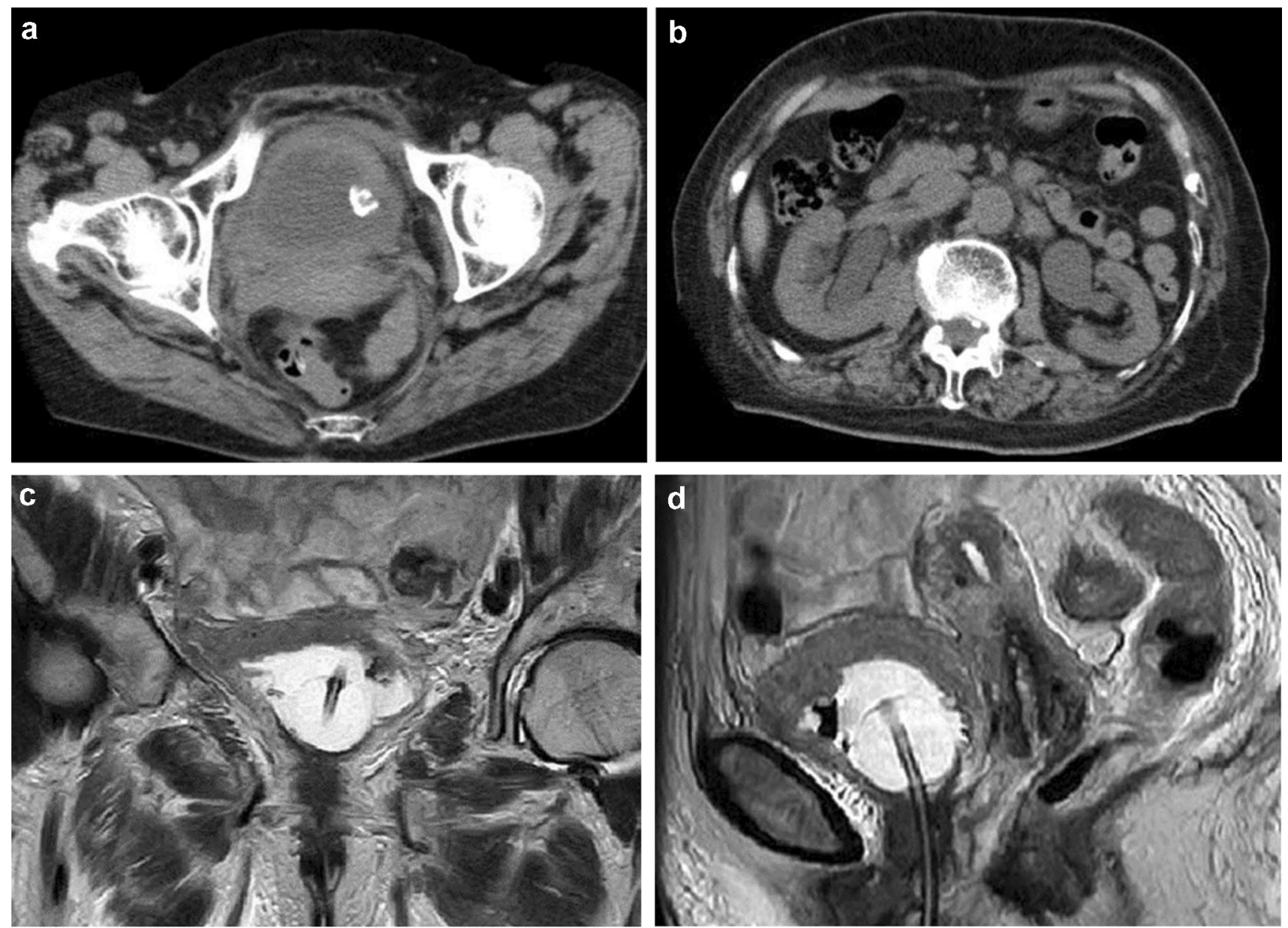

Fig. 1 CT revealed $9 \times 7 \mathrm{~mm}$ bladder tumor at the left top of the bladder and showing thickening of the whole bladder wall (a) and bilateral hydronephrosis (b). MRI showed the bladder trigone at coronal view (c) and relationship between bladder and uterus at sagittal view (d). These views ruled out locally advanced uterine cervical cancer 

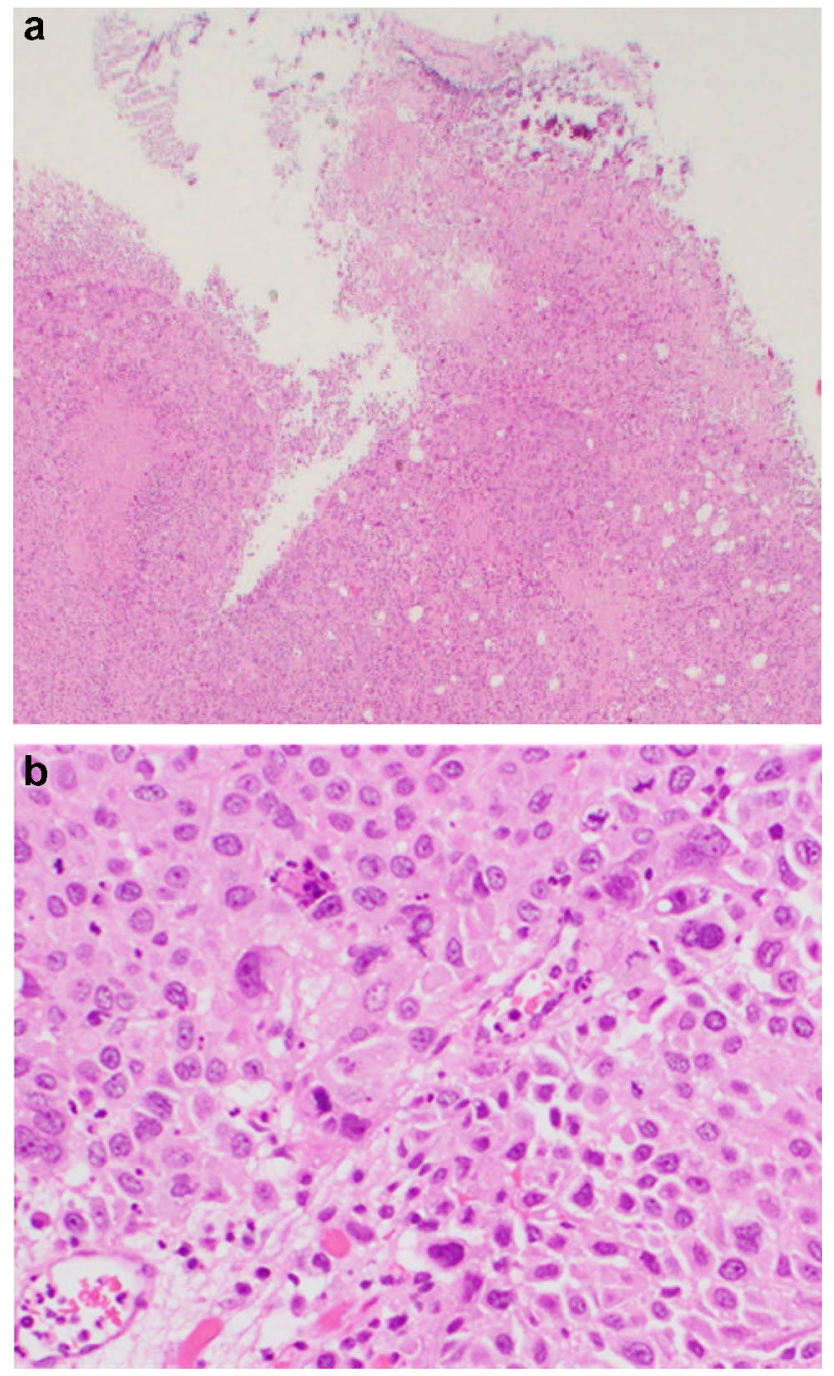

Fig. 2 TURBT specimen. Tumor was mostly located in the lamina propria and muscularis propria. Ulcer was not detected at the superficial mucosa. Tumor shows nodular and sheet-like growth pattern with massive necrosis (a, HE staining, $\times 1.25)$, and large cells with pleomorphic enlarged nuclei with conspicuous mitosis (b, HE staining, $\times 40$ )

As the primary lung cancer biopsy specimen was histologically high-grade malignancy findings with spindleshaped cells as the main component and myxoid interstitium (Fig. 4), while cancer cells in metastatic lesion consist of large circular nuclei and eosinophilic cytoplasm, and MIB-1 index is $82 \%$ and p53 index is $83 \%$ (Fig. 5a, b). According to the results of study and clinical examination, the bladder tumor was diagnosed as metastasis of lung adenocarcinoma. The patient died 19 days after TURBT due to severe disease progression.

\section{Discussion}

Gross hematuria is the most commonly reported presenting symptom in patients with bladder metastasis of lung adenocarcinoma [3, 4]; however, a few studies have reported cases without gross hematuria on presentation $[5,6]$. In the present case, the patient presented with pollakiuria alone, without gross or microscopic hematuria. A possible reason for the absence of microscopic hematuria is that neoplastic cells coming through the hematogenous route are typically located in the lamina propria and/or muscularis propria of the bladder wall [2]. In the present case, the tumor grew widely in the lamina propria, and the superficial mucosa did not become an ulcer (Fig. 2a), so it is considered that there was no bleeding. The disease progression has been very rapid; thus, the tumor that is likely to have been localized to the lamina propria at the first visit invaded the bladder lining at the time of surgery. Aggressive imaging studies should therefore be considered for patients with a previous history of lung adenocarcinoma who present urinary or lower abdominal symptoms, even if a urinalysis reveals no microscopic hematuria. When cystoscopy fails to detect a tumor definitively, CT or MRI may be more sensitive [2].

Bladder cancer metastasis from lung cancer is difficult to distinguish from primary bladder adenocarcinoma. Primary bladder adenocarcinoma accounts for $0.5-2 \%$ of all primary bladder malignancies [7]. The histological features are not useful for differentiating between primary or secondary bladder tumors; thus, immunohistochemistry is crucial to establish a diagnosis. Several markers, used alone or in combination, are reported to be useful for the diagnosis of primary lung adenocarcinoma. TTF-1 is an important transcription factor in the early development of the fetal lung, and plays a crucial role in the molecular pathogenesis of the lung [8]. Moreover, Yue-Chiu Su et al. reported that a combination of TTF-1 positivity, CK7 positivity, and CK20 negativity was highly associated with primary pulmonary adenocarcinoma [9]. In their study, the sensitivity and specificity of this combination of antibodies for a primary lung adenocarcinoma were $60 \%$ and $100 \%$, respectively. Another study also reported a similar result in relation to this immunohistochemistry pattern [10]. This pattern was the same as the present case.

Meanwhile, relationship between patient's catastrophic disease progression and tumor malignant grade is an issue to be considered. An association between the expression of GATA3 and the survival rate in primary lung cancer patients was reported by Hashiguchi et al. [11]. Their study demonstrated that the high expression of GATA3 and vascular invasion were independently associated with poor OS. In the present case, more than $50 \%$ of the tumor cells were positive for GATA3 and vascular invasion was 

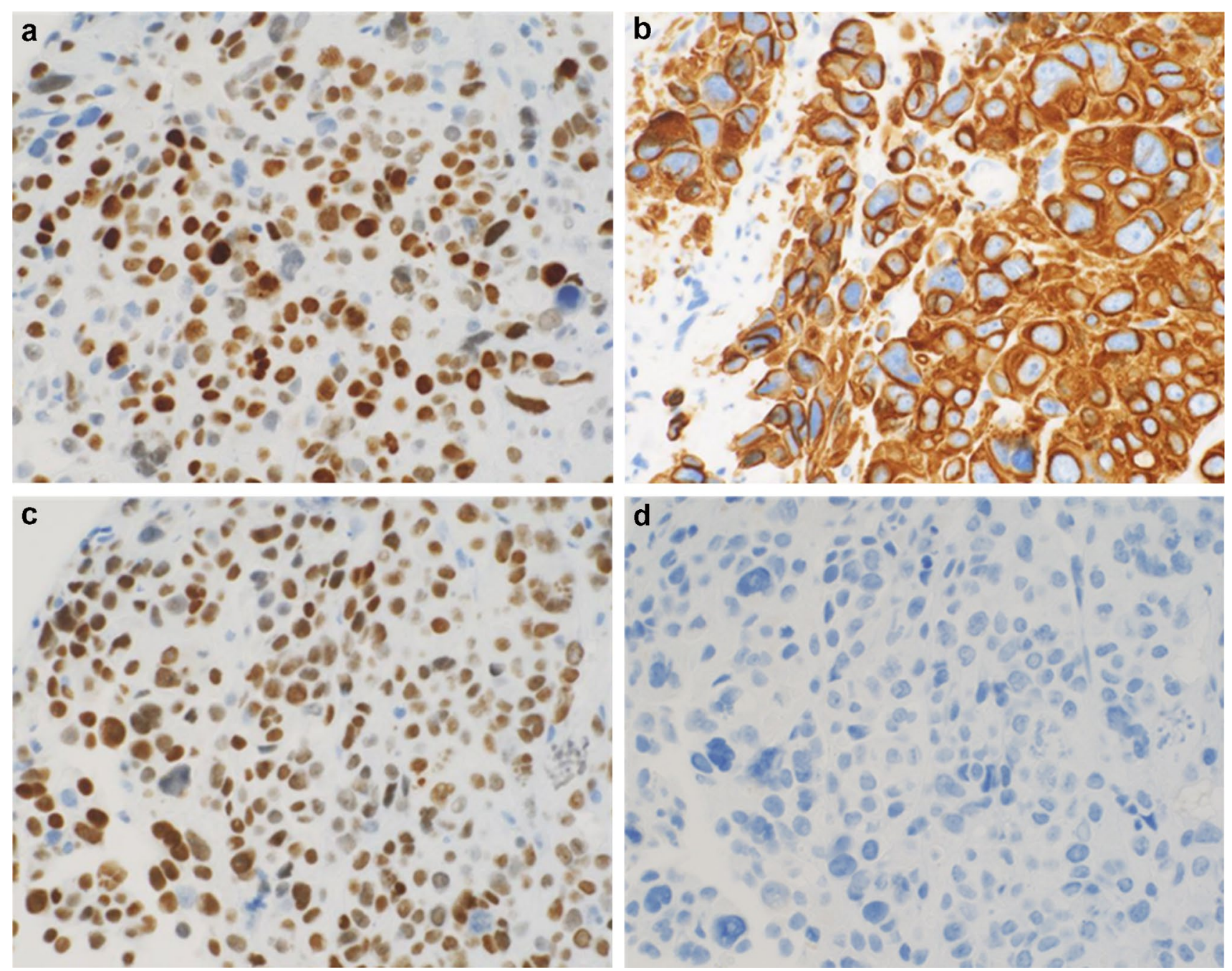

Fig. 3 Immunohistochemical staining of tumor cells was positive for TTF-1 (a), CK7 (b), and GATA3 (c), while negative for CK20 (d)

Fig. 4 Lung biopsy specimen $($ HE stain $\times 40)$ show spindle cells infiltrating with active fibroblast proliferation, which was diagnosed lung adenocarcinoma

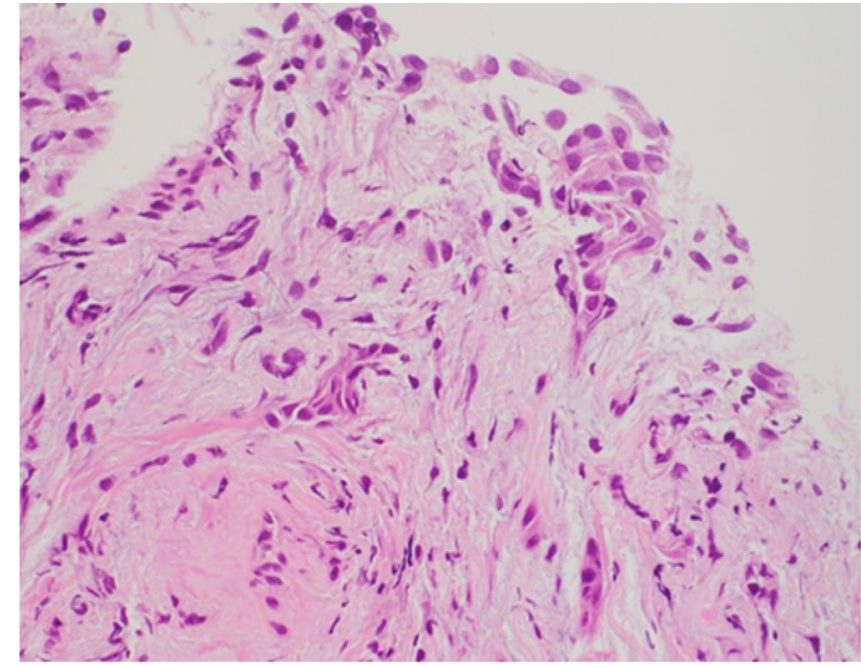



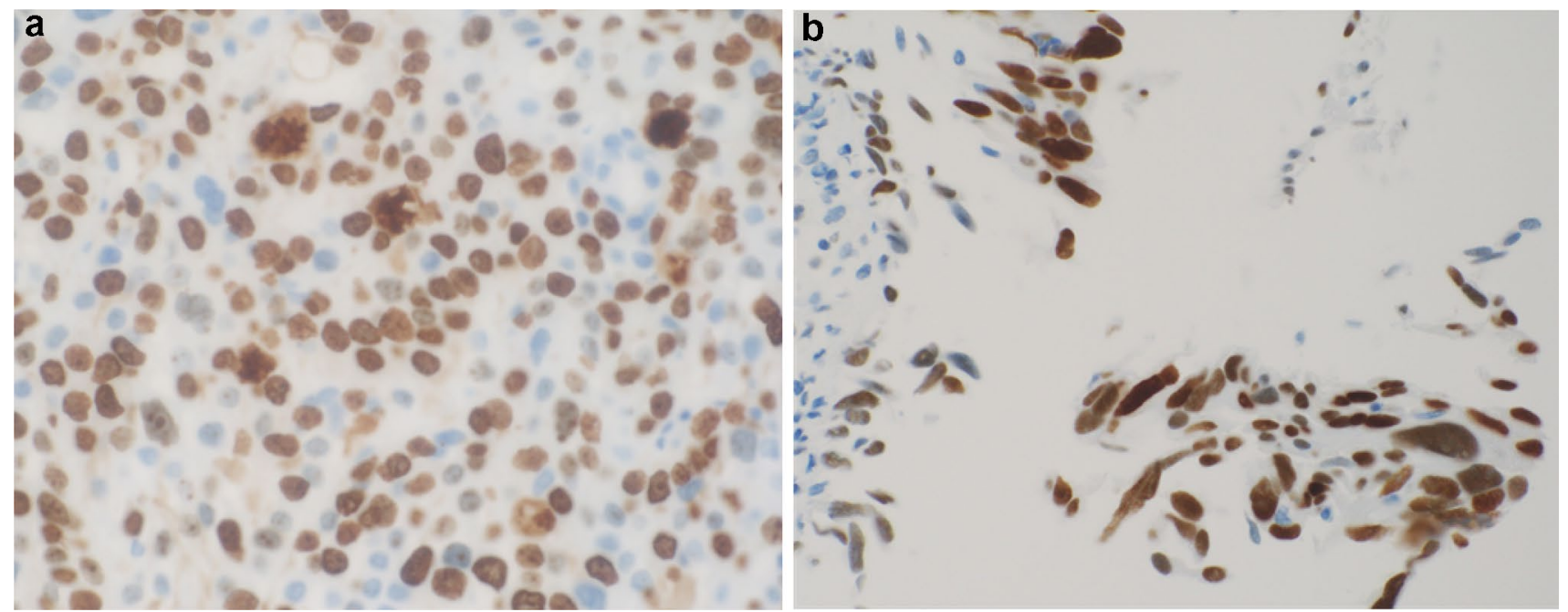

Fig. 5 Immunohistochemical staining of tumor cells was positive for MIB-1 (a) and p53 (b)

also confirmed, which are consistent with the poor prognosis reported by Hashiguchi et al. In addition, the high index of MIB-1 and p53 staining in the present bladder specimen suggests that the metastatic lesion was more malignant. These immunohistochemistry were likely to reflect aggressive invasive behavior of this neoplasm.

In this rare case, a patient with bladder metastasis from lung adenocarcinoma presented with pollakiuria, without microscopic hematuria. When a patient with a previous history of lung adenocarcinoma presents any urinary or lower abdominal symptoms, secondary bladder tumor should be considered in the differential diagnosis, even if urinalysis is negative for microscopic hematuria.

Author contributions TK performed the treatment and made contributions to the acquisition of history, image, drafting the manuscript. MO performed the treatment and reviewed the manuscript to give clinical opinions. CM performed the histological examination of the bladder tumor. IM performed the histological examination of the bladder tumor and lung biopsy specimen, and made substantial contributions to conception and revising it critically for important intellectual content. All authors have read and approved the manuscript.

Funding None to declare.

Availability of data and materials Records and data pertaining to this case are in the patient's secure medical records in Obihiro Kyokai Hospital.

\section{Declarations}

Conflict of interest The authors declare that they have no conflict of interest.
Research involving human participants and/or animals Ethical approval: all procedures performed in studies involving human participants were in accordance with the ethical standards of the institutional and/or national research committee and with the 1964 Helsinki declaration and its later amendments or comparable ethical standards. This article does not contain any studies with animals performed by any of the authors.

Informed consent Written informed consent was obtained from the patient's next of kin for publication of this case report and any accompanying images. A copy of the written consent is available for review by the Editor-in-Chief of this journal.

Open Access This article is licensed under a Creative Commons Attribution 4.0 International License, which permits use, sharing, adaptation, distribution and reproduction in any medium or format, as long as you give appropriate credit to the original author(s) and the source, provide a link to the Creative Commons licence, and indicate if changes were made. The images or other third party material in this article are included in the article's Creative Commons licence, unless indicated otherwise in a credit line to the material. If material is not included in the article's Creative Commons licence and your intended use is not permitted by statutory regulation or exceeds the permitted use, you will need to obtain permission directly from the copyright holder. To view a copy of this licence, visit http://creativecommons.org/licenses/by/4.0/.

\section{References}

1. Bates AW, Baithun SI (2000) Secondary neoplasms of the bladder are histological mimics of non-transitional cell primary tumors: clinicopathological and histological features of 282 cases. Histopathology 36(1):32-40

2. Sanguedolce F, Loizzi D, Sollitto F, Di Bisceglie M, Lucarelli G, Carrieri G, Bufo P, Cormio L (2017) Bladder metastases from lung cancer: clinical and pathological implications: a systematic review. Oncology 92(3):125-134 
3. Raymond KW, Hin TS, Fai KC, Steve CW (2014) Urinary bladder metastasis from lung adenocarcinoma: a rare cause of hematuria. Urol Ann 6(4):359-362

4. Shirakawa H, Kozakai N, Sawafuji M, Sugiura H, Hara S (2012) Urinary bladder metastasis originating from lung adenocarcinoma: a case definitively diagnosed by immunohistochemistry. Urol J 9(2):530-532

5. Cormio L, Sanguedolce F, Di Fino G, Massenio P, Liuzzi G, Bufo P, Carrieri G (2014) Bladder metastasis from lung adenocarcinoma: a difficult differential diagnosis with primary bladder adenocarcinoma. World J Surg Oncol 12:90

6. Modh RA, Corbyons KA, Yeung LL (2013) A rare metastasis to the bladder. Case Rep Urol. https://doi.org/10.1155/2013/789039

7. Thomas DG, Ward AM, Williams JL (1971) A study of 52 cases of adenocarcinoma of the bladder. Br J Urol 43(1):4-15

8. Jerome Marson V, Mazieres J, Groussard O, Garcia O, Berjaud J, Dahan M, Carles P, Daste G (2004) Expression of TTF-1 and cytokeratins in primary and secondary epithelial lung tumors: correlation with histological type and grade. Histopathology 45:125-134

9. Su YC, Hsu YC, Chai CY (2006) Role of TTF-1, CK20, and CK7 immunohistochemistry for diagnosis of primary and secondary lung adenocarcinoma. Kaohsiung J Med Sci 22(1):14-19

10. Oien KA (2009) Pathologic evaluation of unknown primary cancer. Semin Oncol 36:8-37

11. Hashiguchi T, Miyoshi H, Nakashima K, Yokoyama S, Matsumoto R, Murakami D, Mitsuoka M, Takamori S, Akagi Y, Ohshima K (2017) Prognostic impact of GATA binding protein-3 expression in primary lung adenocarcinoma. Hum Pathol 63:157-164

Publisher's Note Springer Nature remains neutral with regard to jurisdictional claims in published maps and institutional affiliations. 